\title{
Population Pharmacokinetics of Cladribine in Patients with Multiple Sclerosis
}

\author{
Radojka M. Savic ${ }^{1}$ Ana M. Novakovic ${ }^{2}$ - Marianne Ekblom ${ }^{3}$. \\ Alain Munafo ${ }^{4} \cdot$ Mats O. Karlsson $^{2}$
}

Published online: 2 March 2017

(c) The Author(s) 2017. This article is published with open access at Springerlink.com

\begin{abstract}
Purpose The aims of this study were to characterize the concentration-time course of cladribine (CdA) and its main metabolite 2-chloroadenine (CAde), estimate interindividual variability in pharmacokinetics (PK), and identify covariates explaining variability in the PK of CdA.

Methods This population PK analysis was based on the combined dataset from four clinical studies in patients with multiple sclerosis (MS): three phase I studies, including one food and one drug-drug interaction study, and one phase III clinical study. Plasma and urine concentration data of CdA and CAde were modeled simultaneously.

Results The analysis comprised a total of $2619 \mathrm{CdA}$ and CAde plasma and urine concentration observations from 173 patients with MS who received an intravenous infusion or oral tablet doses of CdA as a single agent or in combination with interferon (IFN) $\beta-1 \mathrm{a}$. CdA PK data were best described by a three-compartment model, while a onecompartment model best described the PK of CAde. CdA renal clearance $\left(C_{R}\right)$ was correlated with creatinine clearance $\left(\mathrm{CL}_{\mathrm{CR}}\right)$, predicting a decrease in the total
\end{abstract}

Electronic supplementary material The online version of this article (doi:10.1007/s40262-017-0516-6) contains supplementary material, which is available to authorized users.

Mats O. Karlsson

mats.karlsson@farmbio.uu.se

1 Department of Bioengineering and Therapeutic Sciences, University of California San Francisco, San Francisco, CA, USA

2 Department of Pharmaceutical Biosciences, Uppsala University, Box 591, 75124 Uppsala, Sweden

3 Persson Ekblom Sarl, St-Prex, Switzerland

4 Merck Institute for Pharmacometrics, Lausanne, Switzerland clearance of $19 \%, 30 \%$ and $40 \%$ for patients with mild $\left(\mathrm{CL}_{\mathrm{CR}}=65 \mathrm{ml} / \mathrm{min}\right)$, moderate $\left(\mathrm{CL}_{\mathrm{CR}}=40 \mathrm{ml} / \mathrm{min}\right)$ and severe $\left(\mathrm{CL}_{\mathrm{CR}}=20 \mathrm{ml} / \mathrm{min}\right)$ renal impairment, respectively. Food decreased the extent of CdA absorption by $11.2 \%$ and caused an absorption delay. Coadministration with IFN $\beta-1 \mathrm{a}$ was found to increase non- $\mathrm{CL}_{\mathrm{R}}\left(\mathrm{CL}_{\mathrm{NR}}\right)$ by $21 \%$, resulting in an increase of $11 \%$ in total clearance. Conclusions Both CdA and CAde displayed linear PK after intravenous and oral administration of $\mathrm{CdA}$, with $\mathrm{CdA}$ renal function depending on $\mathrm{CL}_{\mathrm{CR}}$.

Trial registration number for study 25643: NCT00213135.

\section{Key Points}

The pharmacokinetics of cladribine (CdA) and its main metabolite 2-chloroadenine (CAde) in patients with multiple sclerosis were described after intravenous and oral administration of CdA.

Both renal and non-renal clearances were estimated for CdA and CAde.

Covariate effects of food on CdA absorption and of coadministration of interferon $\beta$-1a on non-renal clearance were characterized.

\section{Introduction}

Cladribine (2-chloro-2'-deoxyadenosine; CdA), is a synthetic deoxyadenosine analog that is activated by intracellular phosphorylation in specific cell types, resulting in a 
targeted reduction of circulating lymphocytes [1]. Injectable formulations of $\mathrm{CdA}$ have been approved in many countries for the treatment of hematological malignancies [2]. It was hypothesized that CdA may have beneficial effects in the treatment of autoimmune disorders such as multiple sclerosis (MS) due to its selective lymphocyte-reducing properties [2]. This led to the development of an oral formulation of $\mathrm{CdA}$, cladribine tablets, for investigation in relapsing-remitting MS. Cladribine tablets demonstrated significant efficacy compared with placebo on clinical and neuroimaging measures in the large, phase III, 96-week CLARITY (CLAdRIbine Tablets Treating MS OrallY) study [3]. The development program for cladribine tablets, as well as long-term follow-up of patients exposed to cladribine tablets, is ongoing.

The population pharmacokinetics (PK) of CdA have been previously studied in patients with malignancies after administration of parenteral, intravenous and oral solutions [4]. We studied the population PK in patients with MS because physiological differences related to disease pathology in patients with malignancies and those with MS could lead to different kinetic and metabolic behavior for CdA. In addition, the dosing level and schedule and drug formulation that were proposed for use in MS are different from those routinely used in the oncology setting. Data from the main metabolite of CdA, 2-chloroadenine (CAde), were also available for this analysis; it has been documented that metabolite data can provide additional information about the kinetics of the parent drug itself [5].

The overall objective of our analysis was to assess the population PK of CdA and its main metabolite, CAde, after oral tablet administration in patients with relapsingremitting MS. The specific aims of the analysis included quantifying different routes of $\mathrm{CdA}$ elimination (renal and non-renal); assessing the effect of food on CdA absorption and bioavailability; and assessing potential drug-drug interactions of CdA with interferon (IFN) $\beta-1 \mathrm{a}$.

\section{Methods}

\subsection{Clinical Trials}

This population PK analysis evaluated data obtained from four clinical studies of CdA (studies 25803, 26127, 26486 and 25643 [CLARITY; trial registration number: NCT00213135]).

Study 25803 was a phase I, open-label, randomized, two-period, two-sequence crossover study investigating the $\mathrm{PK}$ of $\mathrm{CdA}$ and its metabolites following the administration of a single oral tablet and a single intravenous dose in patients with MS. Sixteen patients were enrolled this study. Patients received CdA $3 \mathrm{mg}$ intravenously as a single 1-h infusion or as a single $10 \mathrm{mg}$ tablet, with a minimum 10-day washout between each treatment. In each treatment period, blood and urine samples were collected for the evaluation of CdA and CAde, pre-dose (within 5-30 min before dosing) and at $0.25,0.5,1,2,3,4,6,8,12,16,24$, $36,48,72,96$ and $120 \mathrm{~h}$ post-dose. Urine was collected pre-dose (within $2 \mathrm{~h}$ before dosing) and at $0-4,4-8,8-12$, 12-24, 24-48 and 48-72 h post-dose.

Study 26127 was a phase I, randomized, two-way, crossover study investigating the effects of food on the PK of CdA administered as oral tablets to patients with MS (16 patients).

Patients were randomized (1:1) to one of two treatment sequences. One group received the treatments in the 'fed then fasted' sequence, and the other group received the treatment in the 'fasted then fed' sequence. Each treatment consisted of a single $10 \mathrm{mg}$ cladribine tablet. In both treatment periods, blood samples for the assessment of $\mathrm{CdA}$ concentration were collected pre-dose (within 5-30 min prior to dosing), and at $0.5,1,1.5,2,3,4,6,8$, $12,16,24,36,48$ and $72 \mathrm{~h}$ post-dose.

Study 26486 was an open-label, multiple-dose study assessing the effects of oral cladribine tablets on the PK of subcutaneous IFN $\beta-1 \mathrm{a}\left(\right.$ Rebif $^{\circledR}$, Merck KGaA, Darmstadt, Germany) and vice versa, as well as the safety of combination treatment in patients with MS. Sixteen patients received one or two $10 \mathrm{mg}$ cladribine tablets administered once-daily for 5 consecutive days (days 1-5). After at least 2 days, patients received IFN $\beta$-1a as follows: $8.8 \mu \mathrm{g}$ three times weekly (days 7-18; six doses), then $22 \mu \mathrm{g}$ three times weekly (days 21-32; six doses), followed by $44 \mu \mathrm{g}$ three times weekly (days 35-60; 12 doses). During the last week of IFN $\beta$-1a treatment, therapy with cladribine tablets (50-100 $\mathrm{mg}$ in total) was coadministered for 5 consecutive days (days 56-60). Blood samples for PK analysis were taken pre-dose and at $0.5,1,1.5,2,3,4,6,8,12,16,24,36$ and $48 \mathrm{~h}$ post-dose at the following times: at the end of the initial treatment course of cladribine tablets (days 4-7); after 2 weeks of IFN $\beta-1$ a $44 \mu$ g (days 45-48); and after the last concomitant administration of cladribine tablets and IFN $\beta$-1a (days 59-62).

Study 25643 (CLARITY) was a phase III, double-blind, placebo-controlled, 96-week study evaluating the safety and efficacy of cladribine tablets in patients with relapsingremitting MS [3]. Patients were randomly assigned (1:1:1 ratio) to receive one of two cumulative doses of cladribine tablets or placebo. Depending on their actual body weight, patients took one or two cladribine $10 \mathrm{mg}$ tablets (or matching placebo) per day over 4-5 days in either (1) weeks 1 and 5 of years 1 and 2, or (2) weeks 1, 5, 9, and 13 of year 1 , followed by weeks 1 and 5 of year 2, for a cumulative dose of 3.5 and $5.25 \mathrm{mg} / \mathrm{kg}$, respectively [3]. Detailed information on the dosing of cladribine tablets in 
the CLARITY study is provided in electronic supplementary Tables 1 and 2. Samples from 125 patients were available for population analysis.

\subsection{Bioanalytical Analysis}

Bioanalytical methods were developed and validated to support the clinical program for cladribine, as described briefly below. CdA and CAde were quantified by liquid chromatography-tandem mass spectrometry (LC-MSMS) methods, validated for human plasma and urine. The lower limit of quantification (LLOQ) for both CdA and CAde was $100 \mathrm{pg} / \mathrm{mL}$, and precision and accuracy of quality controls were assessed for the range of $100-45,000 \mathrm{pg} / \mathrm{mL}$ of CdA and CAde. Intra- and interbatch precision was below $7.5 \%$. Furthermore, intrabatch accuracy of quality controls was between -8.7 and $5.8 \%$, and -1.3 and $4.8 \%$ for CdA and CAde, respectively, and interbatch accuracy of quality controls was included in the range $-1.7-1.6 \%$, and $-0.1-3.3 \%$ for $\mathrm{CdA}$ and CAde, respectively. No interfering chromatographic peaks were observed in blank plasma samples for CdA, CAde and the internal standards.

\subsection{Population Pharmacokinetic (PK) Analysis}

\subsubsection{Structural Model Development}

The model-building procedure included the development of five key models/steps described below and summarized in Table 1.

1. Development of a model for CdA and CAde, both in plasma and urine, after intravenous administration of CdA. Data used for this step were from study 25803 (after intravenous administration only)-Model I.

2. An extension of Model I with the absorption model in the fasted state. Data were extended with the oral administration data from study 25803 (CdA and CAde, both in plasma and urine)—Model II.

3. An extension of Model II with the absorption model in the fed state. Data were extended with the data from study 26127—Model III.

Table 1 Overview of the key modeling steps

\begin{tabular}{lccl}
\hline Model & $\begin{array}{l}\text { No. of } \\
\text { subjects }\end{array}$ & $\begin{array}{l}\text { No. of } \\
\text { samples }\end{array}$ & Studies \\
\hline I & 16 & 397 & 25803 (IV data) \\
II & 16 & 848 & 25803 (IV and oral data) \\
III & 32 & 1264 & 25803,26127 \\
IV & 48 & 1683 & $25803,26127,26486$ \\
V & 173 & 2619 & $25803,26127,26486,25643$ \\
\hline
\end{tabular}

$I V$ intravenous
4. An extension of Model III with the model for multiple dosing of CdA and its interaction with IFN $\beta-1$ a. Data were extended with the data from study 26486Model IV.

5. Extension of Model IV with the data from study 25643-Model V.

PK modeling began with a three-compartment model with first-order (linear) elimination and first-order absorption for oral administration. More complex PK models with respect to absorption and disposition were evaluated for both CdA and CAde.

\subsubsection{Statistical Model Development}

Additive, log-additive, proportional and combined-error models were explored for residual variability. Betweenpatient variability in residual error was evaluated, and additive and/or exponential error models were explored for between-patient variability in the model parameters. A diagonal $\Omega$-structure was initially employed and the inclusion of off-diagonal elements was investigated.

\subsubsection{Covariate Model Development}

The identification of covariates was undertaken using 'Stepwise Covariate Model-Building' using Perl-speaks NONMEM (PsN; version 2.3.2 and higher) [6]. This method involved stepwise testing of linear and non-linear relationships in a forwards inclusion (change in objective function value $[\Delta \mathrm{OFV}]$ of $6.63 ; p<0.01$ for 1 degree of freedom [DF]) and backwards exclusion ( $\triangle \mathrm{OFV}$ of 10.83 ; $p<0.001$ for $1 \mathrm{DF}$ ) procedure [7]. The resultant final model contained covariates that met the predefined statistical criteria. In addition, covariates would only be retained on the basis of their relevance, in view of the purpose of the model. The covariates tested were concomitant IFN $\beta$-1a administration (16 yes/157 no), food state (16 fed/16 fasted/141 unknown), and markers of renal function, i.e. creatinine clearance $\left[\mathrm{CL}_{\mathrm{CR}}\right]$, based on the Cockcroft-Gault equation, sex, age and body weight.

\subsubsection{Modeling Methodology and Software}

The population PK analysis was performed using the nonlinear mixed effects modeling approach using NONMEM (version VI and higher; Icon Development Solutions, Hanover, MD, USA) [8]. The R-based version of Xpose (version 4.0 and higher) was used to produce standard goodness-of-fit plots [6]. Perl (version 5.8.8; http://www. perl.org) and PsN were used for model evaluation and automatic covariate model-building [6]. 
The NONMEM estimation methods used were firstorder conditional (FOCE) and FOCE with interaction (FOCEI). The stability of NONMEM models was assessed on the basis of acceptable basic goodness-of-fit plots, number of significant digits $\geq 3$ for all estimated parameters, successful covariance step, estimates of typical patient parameters ( $\Theta^{\prime}$ s) not close to a boundary, and stability check performed for a selected basic model (the model finds the global minimum when the initial values are altered in each direction [i.e. each parameter, one at a time] by a large factor [10 in this analysis]). Model selection was based on the comparison of full versus reduced models using the log-likelihood criterion (the difference in the minimum OFV between hierarchical models was assumed to be Chi-square distributed with degrees of freedom equal to the difference in the number of parameters between models), goodness-of-fit plots (e.g. relevant residuals against time randomly distributed around zero), and scientific plausibility of the model.

\subsubsection{Model Evaluation}

To evaluate whether the estimated fixed- and random-effect parameters adequately describe data, 1000 Monte Carlo simulation replicates of the original dataset were generated using each of the five key population PK models (Model I through Model V). The data were plotted versus time along with the summary statistics computed from the simulated data with 5th, 50th, and 95th percentiles including uncertainty. The coincidence between the original data and simulated data demonstrated the predictive ability of fixed effects parameters in the final model. The visual predictive check was stratified on variables of interest, such as route of administration, food state and coadministration with IFN $\beta$-1a.

A stratified non-parametric bootstrap procedure was performed to assess the uncertainty and stability of all key models. Confidence intervals were calculated from the successfully converged runs, and a large, non-parametric bootstrap ( $n=1000$ ) was performed for Models I and II only due to long run times. A shorter non-parametric bootstrap including 30 and 100 samples was performed to assess standard errors for Models IV and V, respectively.

\section{Results}

\subsection{Data}

A summary of the studies included in this analysis is provided in Table 2. PK profiles from a total of 173 patients were used in this analysis and a summary of the study demographics is shown in Table 3. The original dataset contained 4790 concentration-time records; $45 \%$ of records were excluded for various reasons, such as being below the limit of quantification (BLQ) and missing sampling times, leaving 2619 concentration records for population analysis. Most of the excluded data (96.5\%) were BLQ records, coming mostly from two studies: approximately one-third of the BQL samples from study 25803 with an extended follow-up period (up to $120 \mathrm{~h}$ ), and approximately two-thirds of the BQL samples from study 25643, where approximately half the samples were collected before the administration of the CdA dose.

\subsection{Population PK Model}

\subsubsection{Structural Model Development}

Model I A three-compartment model best described the PK of $\mathrm{CdA}$ after intravenous administration, and a one-compartment model best described the PK of the main $\mathrm{CdA}$ metabolite, CAde. Available urine data enabled estimation of renal clearance $\left(\mathrm{CL}_{\mathrm{R}}\right)$ for both $\mathrm{CdA}$ and CAde. For CdA, $\mathrm{CL}_{\mathrm{R}}$ was implemented as a linear function of $\mathrm{CL}_{\mathrm{CR}}$, while renal elimination of the metabolite was best described with a saturable model. Separate non- $\mathrm{CL}_{\mathrm{R}}\left(\mathrm{CL}_{\mathrm{NR}}\right)$ and $\mathrm{CL}_{\mathrm{R}}$ for both the parent drug and metabolite could be estimated. The fraction of metabolized drug could be assessed as $\mathrm{CL}_{\mathrm{NR}} /$ total clearance $=0.536$. Renal elimination of $\mathrm{CdA}$

Table 2 Summary of the studies included in the population PK analysis

\begin{tabular}{|c|c|c|c|c|c|c|c|}
\hline \multirow[t]{2}{*}{ Study } & \multirow[t]{2}{*}{ Phase } & \multirow[t]{2}{*}{$n^{\mathrm{a}}$} & \multicolumn{2}{|c|}{ No. of CdA samples ${ }^{b}$} & \multicolumn{2}{|c|}{ No. of CAde samples ${ }^{b}$} & \multirow[t]{2}{*}{ Treatment: administration and dose (cumulative) } \\
\hline & & & Plasma & Urine & Plasma & Urine & \\
\hline 25803 & I & 16 & 404 & 166 & 189 & 89 & CdA: $3 \mathrm{mg}$ IV infusion/10 mg single oral doses \\
\hline 26127 & $\mathrm{I}$ & 16 & 416 & - & - & - & CdA: $10 \mathrm{mg}$ single oral doses \\
\hline 26486 & $\mathrm{I}$ & 16 & 419 & - & - & - & CdA: $1.75 \mathrm{mg} / \mathrm{kg}$ orally over 8 weeks + IFN $\beta-1 \mathrm{a}$ \\
\hline 25643 & III & 125 & 470 & - & 466 & - & CdA: 3.5 or $5.25 \mathrm{mg} / \mathrm{kg}$ orally over 2 years \\
\hline
\end{tabular}

$P K$ pharmacokinetic, $C d A$ cladribine, $C A d e$ 2-chloroadenine, $I V$ intravenous, $I F N$ interferon, $R R M S$ relapsing-remitting multiple sclerosis

${ }^{\text {a }}$ Number of CdA-treated RRMS patients included in the population PK analysis

b Total number of samples available for the population PK analysis 
Table 3 Summary of the patient demographics

\begin{tabular}{|c|c|c|c|c|c|}
\hline Variable & Study 25803 & Study 26127 & Study 26486 & Study 25643 & Overall \\
\hline \multicolumn{6}{|c|}{ Age, years } \\
\hline Median & 36 & 29.5 & 48.5 & 40 & 40 \\
\hline Range & $27-54$ & $20-58$ & $32-54$ & $19-65$ & $19-65$ \\
\hline \multicolumn{6}{|c|}{ Body weight, $\mathrm{kg}$} \\
\hline Median & 77.5 & 70.5 & 69.5 & 68.9 & 69.2 \\
\hline Range & $51-99$ & $54-97$ & $50-93$ & $48.5-116.1$ & $48.5-116.1$ \\
\hline \multicolumn{6}{|c|}{$\operatorname{Sex}[n(\%)]$} \\
\hline Male & $10(62.5)$ & $4(25)$ & $6(37.5)$ & $39(31.2)$ & $59(34.1)$ \\
\hline Female & $6(37.5)$ & $12(75)$ & $10(62.5)$ & $86(68.8)$ & $114(65.9)$ \\
\hline \multicolumn{6}{|c|}{$\mathrm{CL}_{\mathrm{CR}}, \mathrm{mL} / \mathrm{min}$} \\
\hline Median & 109.2 & 121.2 & 103.7 & 105.8 & 107.9 \\
\hline Range & $70.2-139.8$ & $94.9-150.8$ & $67.1-164.9$ & $49.6-244.4$ & $49.6-244.4$ \\
\hline
\end{tabular}

$C L_{C R}$ creatinine clearance

accounted for approximately $50 \%$ of total elimination, while renal elimination of the metabolite was minor. Metabolite profiles were well described, as indicated by the low residual variability (13.4\%), even though no separate interindividual variability was estimated in the metabolite disposition parameters.

Model II A first-order absorption model was sufficient to describe the absorption of CdA in the fasted state. The introduction of absorption delay models, such as a lag-time model and a transit-compartment model, offered some improvement in the fit. However, the observed delay could be assigned to only a few individuals and therefore it was not kept in the model. Bioavailability was estimated to be $45.5 \%$.

Model III Inclusion of the data from the fed state, with the aim of assessing the effect of food on absorption parameters, required elaboration of the absorption model to describe the effect of food on the absorption delay. The transit-compartment model best described the absorption delay in the data from the fed state. This model offered an improvement compared with first-order absorption with a lag time. Mean transit time was estimated to be $1.04 \mathrm{~h}$, and the number of transit compartments was estimated to be 2.44. Bioavailability decreased with food by approximately $14 \%$.

Model IV Data from the multiple-dosing schedule (study 26486) did not contain information on food state and therefore absorption parameters were modeled separately. A potential effect of IFN $\beta$-1a coadministration on CdA bioavailability and $\mathrm{CL}_{\mathrm{NR}}$ was tested. The bioavailability of CdA in study 26486 was generally lower compared with other studies; however, no significant differences in bioavailability were found between $\mathrm{CdA}$ administered alone and CdA administered with IFN $\beta-1 \mathrm{a}$. IFN $\beta-1 \mathrm{a}$ coadministration led to an increase in $\mathrm{CL}_{\mathrm{NR}}$ of $\mathrm{CdA}$ of approximately $22 \%$, which was statistically significant $(p<0.05)$ and associated with a slight improvement in predictive checks.

Model $V$ The addition of phase III data only required the addition of a lag time, which improved the fit during the absorption phase. Overall, with the addition of phase III data, parameters changed very little compared with the parameters from the final phase I model. Due to sparse sampling at late time points, the phase III data were lacking information relating to $\mathrm{CL}_{\mathrm{R}}$; however, due to the presence of metabolite data, they supported good estimation of $\mathrm{CL}_{\mathrm{NR}}$ and bioavailability. Good correspondence between phases I and III was observed for almost all parameters, although some changes in the rate of absorption were observed. The population parameter point estimates and their uncertainty, assessed via non-parametric bootstrap $(n=100)$, are shown in Table 4 , and the structure of the final model is shown in Fig. 1.

The final model was used to generate cladribine profiles following 5 days of cladribine treatment (dose $=10 \mathrm{mg}$ ) for a typical patient with normal renal function. CdA concentrations were then predicted using three different values of $\mathrm{CL}_{\mathrm{CR}}$, mimicking 3 degrees of severity of renal impairment, by incorporating those values into the developed model. The predicted decrease in total clearance was $19 \%, 30 \%$ and $40 \%$ for patients with mild $\left(\mathrm{CL}_{\mathrm{CR}}=65 \mathrm{ml} /\right.$ $\mathrm{min})$, moderate $\left(\mathrm{CL}_{\mathrm{CR}}=40 \mathrm{ml} / \mathrm{min}\right)$ and severe $\left(\mathrm{CL}_{\mathrm{CR}}=20 \mathrm{ml} / \mathrm{min}\right)$ renal impairment, respectively.

\subsubsection{Covariate Model Development}

Covariate analysis revealed no significant influence of demographic covariates (body weight, age and sex) on PK parameters, in addition to their impact on renal function mediated though $\mathrm{CL}_{\mathrm{CR}}$. Additional investigation of individual predicted $\mathrm{CL}_{\mathrm{NR}}$ against aspartate aminotransferase (AST), alanine aminotransferase (ALT) and bilirubin did 
Table 4 Population PK parameter estimates from the final model

\begin{tabular}{|c|c|c|}
\hline Parameter & Final model & $\mathrm{RSE}, \%^{\mathrm{a}}$ \\
\hline \multicolumn{3}{|l|}{ Cladribine } \\
\hline $\mathrm{CL}_{\mathrm{R}}$ coefficient $^{\mathrm{b}}$ (typical patient with $\mathrm{CL}_{\mathrm{CR}}=6.31$ ), $\mathrm{L} / \mathrm{h}^{\mathrm{c}}$ & $3.52(22.2)$ & 9.26 \\
\hline $\mathrm{CL}_{\mathrm{NR}}, \mathrm{L} / \mathrm{h}$ & 23.4 & 9.58 \\
\hline Central volume, $\mathrm{L}$ & 44.0 & 22.77 \\
\hline Intercompartmental $\mathrm{Q}_{3}, \mathrm{~L} / \mathrm{h}$ & 14.3 & 7.73 \\
\hline Intercompartmental $\mathrm{Q}_{4}, \mathrm{~L} / \mathrm{h}$ & 53.7 & 19.06 \\
\hline Peripheral volume $\mathrm{V}_{3}, \mathrm{~L}$ & 347 & 6.07 \\
\hline Peripheral volume $\mathrm{V}_{4}, \mathrm{~L}$ & 89.5 & 7.97 \\
\hline Absorption rate constant, $\mathrm{h}^{-1}$ & 1.08 & 21.14 \\
\hline Absorption rate constant (unknown/fed state), $\mathrm{h}^{-1}$ & 1.03 & 11.62 \\
\hline Bioavailability & 0.456 & 7.03 \\
\hline Bioavailability (unknown/fed state) & 0.4 & 5.28 \\
\hline Lag time for phase III, $\mathrm{h}$ & 0.319 & 12.41 \\
\hline Mean transit time (fed state), $\mathrm{h}$ & 0.910 & 11.03 \\
\hline Number of transit compartments & 2.24 & 27.15 \\
\hline Fold increase in $C_{N R}$ in the presence of IFN $\beta$-1a & 1.21 & 8.46 \\
\hline $\mathrm{BSV}_{\mathrm{CLNR}}$ & 0.00574 & 64.41 \\
\hline $\mathrm{BSV}_{\mathrm{V}}$ & 0.209 & 72.51 \\
\hline $\mathrm{BSV}_{\mathrm{Q} 3, \mathrm{Q} 4, \mathrm{~V} 3, \mathrm{~V} 4}$ & 0.0365 & 28.47 \\
\hline $\mathrm{BSV}_{\mathrm{Ka}}$ & 0.102 & 62.53 \\
\hline $\mathrm{BSV}_{\mathrm{F}}^{\mathrm{d}}$ & 0.223 & 19.13 \\
\hline $\mathrm{BSV}_{\text {Residual variability }}$ & 0.159 & 16.66 \\
\hline RUV plasma (intravenous), $\%$ & 20.0 & 11.21 \\
\hline RUV plasma (oral), \% & 34.7 & 16.19 \\
\hline RUV plasma (oral; studies 26127, 26486), \% & 22.8 & 5.84 \\
\hline RUV plasma (oral; study 25643), \% & 35.3 & 6.74 \\
\hline RUV urine, \% & 87.1 & 10.89 \\
\hline \multicolumn{3}{|l|}{ 2-Chloroadenine } \\
\hline $\mathrm{CL}_{\mathrm{R}}^{\mathrm{e}}\left(\mathrm{V}_{\max }\right), \mu \mathrm{g} / \mathrm{h}$ & 0.00280 & 25.53 \\
\hline $\mathrm{CL}_{\mathrm{R}}^{\mathrm{e}}(\mathrm{Km}), \mathrm{ng} / \mathrm{L}$ & 0.0114 & 58.14 \\
\hline Apparent hepatic CL, $\mathrm{L} / \mathrm{h}^{\mathrm{f}}$ & 653 & 10.64 \\
\hline Apparent central volume $\mathrm{V}, \mathrm{L}^{\mathrm{f}}$ & 365 & 13.27 \\
\hline RUV plasma, $\%$ & 34.3 & 19.64 \\
\hline RUV plasma (study 25643), $\%$ & 31.8 & 76.38 \\
\hline RUV urine, $\%$ & 104 & 14.32 \\
\hline
\end{tabular}

$B S V$ between subject variability for the random-effects distribution of the parameter, $C L$ clearance, $C L_{C R}$ creatinine clearance, $C L_{N R}$ non-renal clearance, $C L_{R}$ renal clearance, $F$ bioavailability, IFN interferon, $K a$ absorption rate constant, $\mathrm{Km}$ metabolite concentration at which the half maximal renal clearance rate is achieved, $P K$ pharmacokinetic, $Q_{3}$ intercompartment clearance between the central and first peripheral compartment, $Q_{4}$ intercompartment clearance between the central and second peripheral compartment, $R S E$ relative standard error, $R U V$ residual unexplained variability (proportional component), $V$ volume of distribution, $V_{3}$ peripheral one-compartment volume of distribution, $V_{4}$ peripheral two-compartment volume of distribution, $V_{\max }$ maximal $\mathrm{CL}_{\mathrm{R}}$ rate for metabolite

${ }^{\text {a }}$ RSEs from bootstrap $(n=100)$ in NONMEM

b Scaled parameter to be dimensionless. Original parameter estimated in NONMEM run had units of L/h

${ }^{c} \mathrm{CL}_{\mathrm{R}}, \mathrm{L} / \mathrm{h}=$ coefficient $\times \mathrm{CL}_{\mathrm{CR}}, \mathrm{L} / \mathrm{h}$

d Variance on a logit scale

${ }^{\text {e }} \mathrm{CL}_{\mathrm{R}}=V_{\max } \times \mathrm{CM} /(\mathrm{KM}+\mathrm{CM})$; saturable elimination, where $\mathrm{CM}=$ metabolite concentration

${ }^{\mathrm{f}}$ Corrected for the fraction metabolized to 2-chloroadenine 


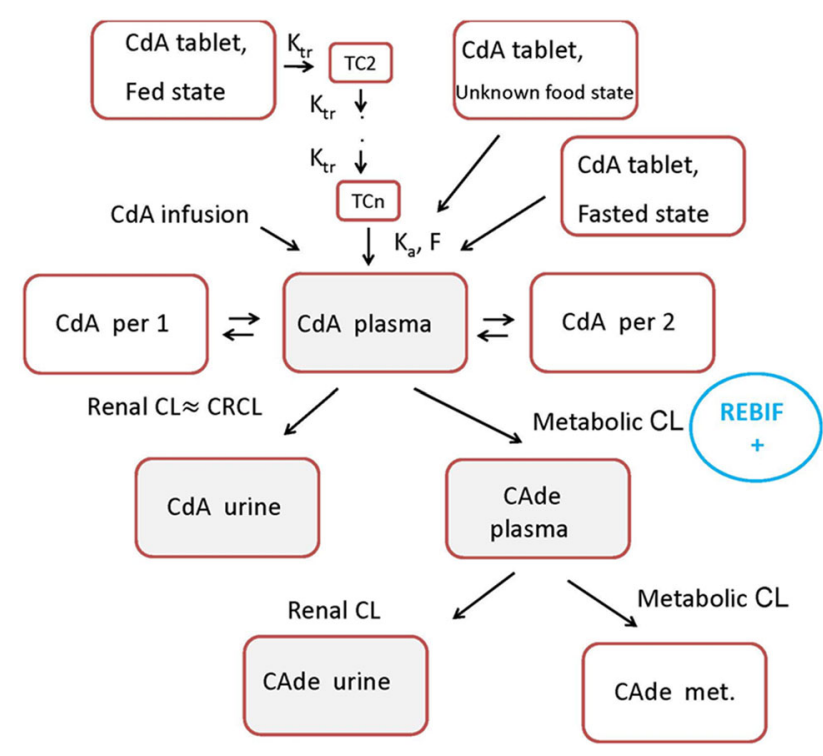

Fig. 1 Schematic representation of the final model. $C d A$ cladribine, $K a$ absorption rate constant, $K t r$ transfer rate constant, $F$ bioavailability, TC2 second transit compartment, TCn: $n$th transit compartment, per 1 first peripheral compartment, per 2 second peripheral compartment, $C L$ clearance, $C R C L$ creatinine clearance, CAde 2-chloroadenine

not show any association between liver function markers and $\mathrm{CL}_{\mathrm{NR}}$.

\subsubsection{Model Evaluation}

The final model was evaluated by a visual predictive check stratified on variables of interest, such as route of administration, food state and coadministration with IFN $\beta-1$ a (Figs. 2, 3, 4). The stratified non-parametric bootstrap ( $n=30-1000$ ) was performed for all key models in order to compute relative standard errors (RSE) for parameters.

\section{Discussion}

This analysis characterized the population PK of both CdA and CAde following oral and intravenous administration of $\mathrm{CdA}$ in patients with relapsing-remitting MS. The final population PK model provided a good description of the PK data of CdA in patients with MS. Goodness-of-fit criteria revealed that the final model was consistent with the observed data and no systematic bias remained. The model evaluation results provided evidence that both the fixed and random effect components of the final model were reflective of the observed data.

The PK data were described reasonably well using a three-compartment PK model, which is consistent with previous findings [4]. Availability of the urine data enabled separation of the $\mathrm{CL}_{\mathrm{R}}$ and $\mathrm{CL}_{\mathrm{NR}}$, and the typical population parameter estimates from the final model for these two elimination routes were $\mathrm{CL}_{\mathrm{R}}=22.2 \mathrm{~L} / \mathrm{h}$ and $\mathrm{CL}_{\mathrm{NR}}=23.4 \mathrm{~L} / \mathrm{h}$, indicating that both elimination pathways are equally represented. The previous population PK analysis of $\mathrm{CdA}$ reported a value for total clearance of 39.3 L/h [4]; however, that analysis was carried out in terminally ill cancer patients, who are likely to have decreased function of vital organs and therefore lower clearance values. Once the differences in the mean $\mathrm{CL}_{\mathrm{CR}}$ between two populations are taken into account $(4.86 \mathrm{~L} / \mathrm{h}$ in oncology patients compared with $6.31 \mathrm{~L} / \mathrm{h}$ in the MS population), the estimates of clearance become comparable (39.3 vs. $40.5 \mathrm{~L} / \mathrm{h}$ ). Moreover, the previous analysis was a retrospective analysis where the data were collected over long time periods and using different bioanalytical methods, which may not provide fully comparable results. $\mathrm{CL}_{\mathrm{R}}$ appeared to be higher than the glomerular filtration rate, indicating that other mechanisms, such as active secretion, are involved in $\mathrm{CdA}$ renal elimination, which is also consistent with previous reports [9].

Bioavailability of $\mathrm{CdA}$ after oral administration was $45.6 \%$, which is consistent with previous findings $[10,11]$. Coadministration of $\mathrm{CdA}$ with food appeared to decrease bioavailability to $40.5 \%$, which is not expected to have a clinically meaningful impact. In addition, food also appeared to delay absorption.

Coadministration of $\mathrm{CdA}$ with IFN $\beta$-1a appeared to have an effect on $\mathrm{CdA}$ clearance, which increased $\mathrm{CL}_{\mathrm{NR}}$ by $21 \%$, resulting in an increase of total clearance by approximately $11.1 \%$. However, although the modeling pointed to this effect on $\mathrm{CL}_{\mathrm{NR}}$, it could also have been modeled on its bioavailability. Given the data available, it was not really possible to discriminate between the two. Furthermore, the observed effect could also be due to a period effect or interoccasion variability; however, these effects were confounded (owing to the study design) and further elaboration could not be supported with the available data. PK profiles of patients receiving $\mathrm{CdA}$ alone or coadministered with pantoprazole were also evaluated and no clinically relevant drug-drug interaction was found.

Covariates included in the model were fasted/fed state on absorption parameters, IFN $\beta$-1a effect on $\mathrm{CL}_{\mathrm{NR}}$, and $\mathrm{CL}_{\mathrm{CR}}$ on $\mathrm{CL}_{\mathrm{R}}$ of $\mathrm{CdA}$. Sex, age and body weight have also been investigated and were not associated with the PK of CdA (except for their impact on renal function mediated though $\mathrm{CL}_{\mathrm{CR}}$ ). A graphical investigation of individual predicted $\mathrm{CL}_{\mathrm{NR}}$ against $\mathrm{AST}, \mathrm{ALT}$ and bilirubin did not show any association between liver function markers and $\mathrm{CL}_{\mathrm{NR}}$, and the previous population analysis of $\mathrm{CdA}$ in cancer patients also revealed no significant covariate effect [4].

The PK of the main CdA metabolite, CAde, were well described by a one-compartment model. Apparent $\mathrm{CL}_{\mathrm{NR}}$ 
Fig. 2 Visual predictive checks for CdA and CAde in plasma of intravenously and orally administered CdA. Light blue shaded area indicates simulated median with uncertainty; pink shaded area indicates simulated 5th and 95th percentiles with indicates observed median; dashed blue line indicates observed 5th and 95th samples from 16 subjects; b based on 211 samples from 16 subjects; $\mathbf{c}$ based on 470 samples from 125 subjects; d based on 81 samples from 16 subjects; e based on 108 samples from 16 subjects; and f based on 466 samples from 125 subjects. $C d A$ cladribine, md multiple dosing, CAde uncertainty; solid blue line percentiles. a Based on 193 2-chloroadenine, $I V$ intravenous
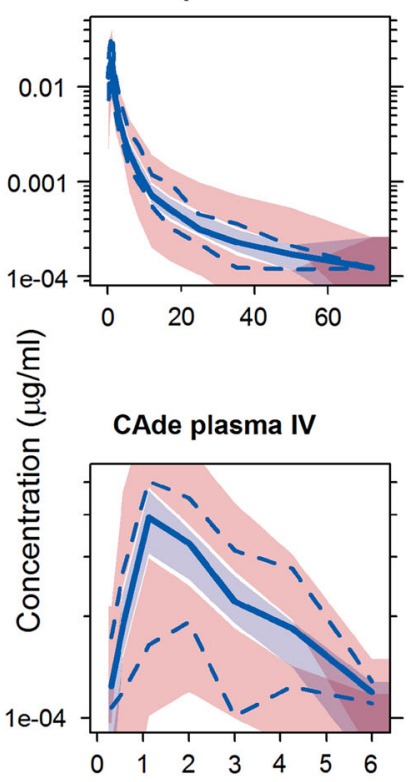

CdA plasma IV
CdA plasma oral

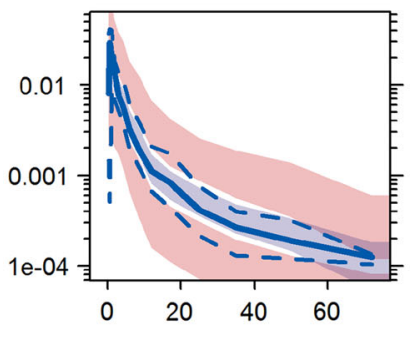

CAde plasma oral

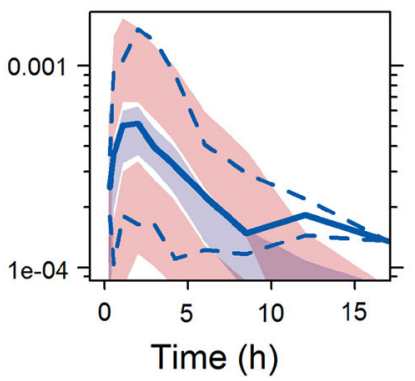

CdA plasma oral,md

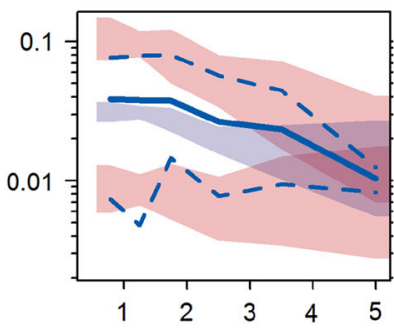

CAde plasma oral,md

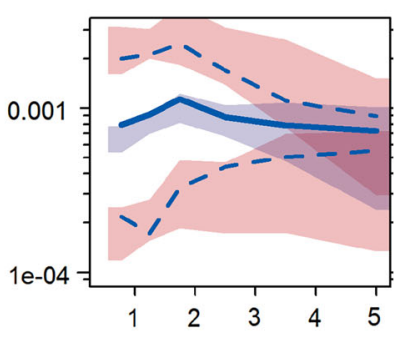

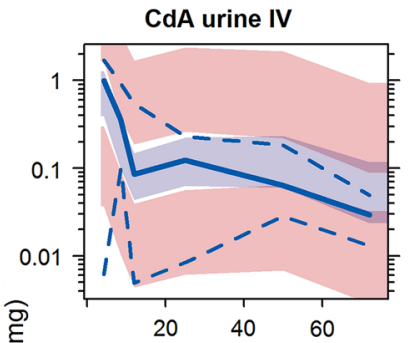

CAde urine IV

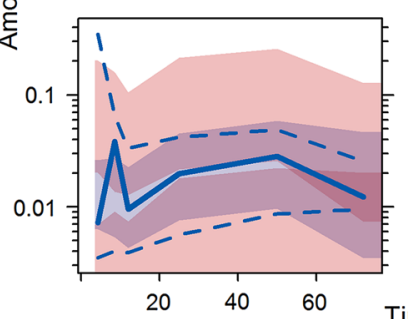

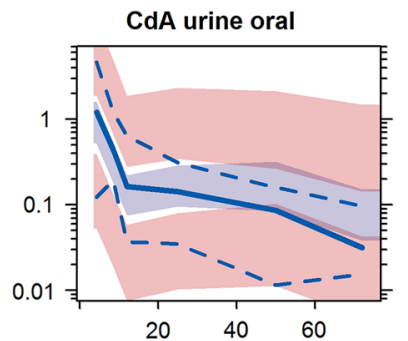

CAde urine oral

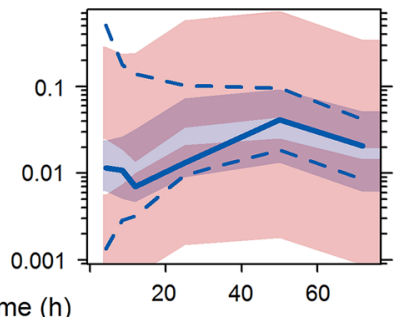

Fig. 3 Visual predictive checks for $\mathrm{CdA}$ and CAde in urine of intravenously and orally administered CdA. Light blue shaded area indicates simulated median with uncertainty; pink shaded area indicates simulated 5th and 95th percentiles with uncertainty; solid blue line indicates observed median; dashed blue line indicates observed 5th and 95th percentiles. a Based on 83 samples from 16 subjects; b based on 83 samples from 16 subjects; c based on 40 samples from 16 subjects; $\mathbf{d}$ based on 49 samples from 16 subjects. $C d A$ cladribine, $C A d e$ 2-chloroadenine, $I V$ intravenous

and volume of distribution for CAde were found to be $653 \mathrm{~L} / \mathrm{h}$ and $365 \mathrm{~L}$, respectively. The availability of urine data for CAde enabled separation of the renal and nonrenal elimination pathways for CAde. Renal elimination appeared to be saturable and to represent a minor elimination pathway. The visual predictive check of Model II indicated a possible second compartment for CAde; however, this further extension of the metabolite model was not supported by the limited data. Furthermore, the indication of a second compartment could be spurious, driven by sporadic visible observations above the quantification limit (most of the metabolite observations were below the LLOQ at these late time points).

The estimated variability in most CdA PK parameters was modest. Moreover, the rather low variability in bioavailability demonstrated the consistent performance of the tablet formulation with regard to drug release and dissolution. Residual variability of urinary data was rather high (close to $90 \%$ ). Urinary data are often more erratic than plasma, and, in these profiles, some inconsistent patterns were observed, which may have made it difficult to separate the variability sources. The estimated variability in $\mathrm{CL}_{\mathrm{R}}$ is low, and, in the final model, almost all variability in the urinary output is attributed to residual error.

\section{Conclusions}

The PK of CdA and its main metabolite, CAde, in patients with MS were described after both intravenous and oral administration of $\mathrm{CdA}$, with estimation of $\mathrm{CL}_{\mathrm{R}}$ and $\mathrm{CL}_{\mathrm{NR}}$ for both compounds. Food appeared to delay $\mathrm{CdA}$ absorption and to slightly decrease the extent of absorption. Coadministration of IFN $\beta$-1a slightly increased the $\mathrm{CL}_{\mathrm{NR}}$ of $\mathrm{CdA}$, without a significant impact on $\mathrm{CdA}$ exposure, owing to the evenly split clearance between non-renal and 


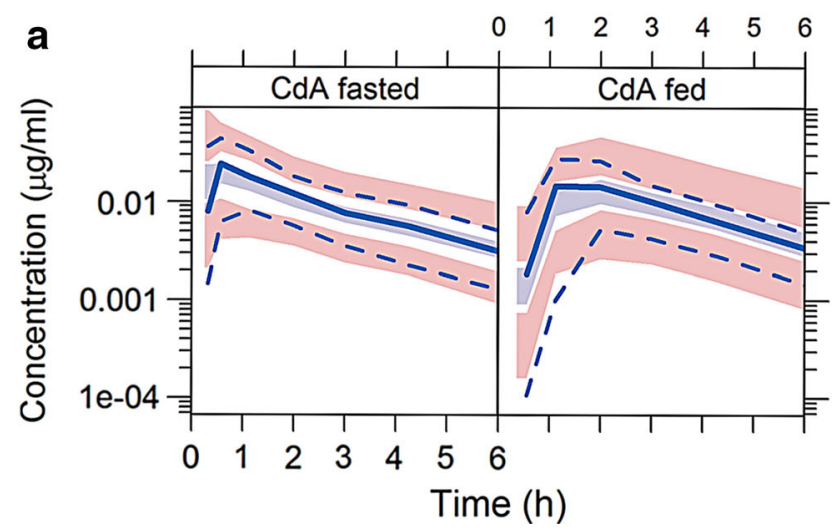

Fig. 4 Visual predictive checks for $\mathrm{CdA}$ in plasma after oral administration of $\mathrm{CdA}$ in $\mathbf{a}$ fasted and fed conditions, and $\mathbf{b}$ with and without IFN $\beta-1$ a coadministration. Light blue shaded area indicates simulated median with uncertainty; pink shaded area indicates simulated 5th and 95th percentiles with uncertainty; solid

renal components. The proposed model explained the PK of CdA in great detail thanks to the informative design of several clinical studies.

Acknowledgements Editorial assistance in the preparation of this article was provided by Samantha Holmes at ACUMED ${ }^{\circledR}$ (Tytherington, UK) and was funded by Merck Serono S.A., Geneva, Switzerland.

At the time of preparation of this study, Radojka M. Savic was employed at the Department of Pharmaceutical Biosciences, Uppsala University, Uppsala, Sweden, and Marianne Ekblom was employed at Merck Serono S.A., Geneva, Switzerland.

\section{Compliance with Ethical Standards}

Funding This study was supported by Merck Serono S.A., Geneva, Switzerland, an affiliation of Merck KGaA, Darmstadt, Germany.

Conflict of interest Dr. Savic and Dr. Karlsson were/are, respectively, employees of the Uppsala University, which received financial support for performing this analysis. Mrs Novakovic has received financial support from Merck Serono for attending a symposia. Dr. Ekblom was an employee of Merck Serono S.A., Geneva, Switzerland, an affiliation of Merck KGaA, Darmstadt, Germany, at the time of the analysis. Dr. Munafo is an employee of Merck Institute for Pharmacometrics, Lausanne, Switzerland.

Ethical approval All procedures performed in studies involving human participants were in accordance with the ethical standards of the institutional and/or national research committee and with the 1964 Helsinki declaration and its later amendments or comparable ethical standards.

Informed consent Informed consent was obtained from all individual participants included in the studies.

Open Access This article is distributed under the terms of the Creative Commons Attribution-NonCommercial 4.0 International License (http://creativecommons.org/licenses/by-nc/4.0/), which permits any noncommercial use, distribution, and reproduction in any medium, provided you give appropriate credit to the original

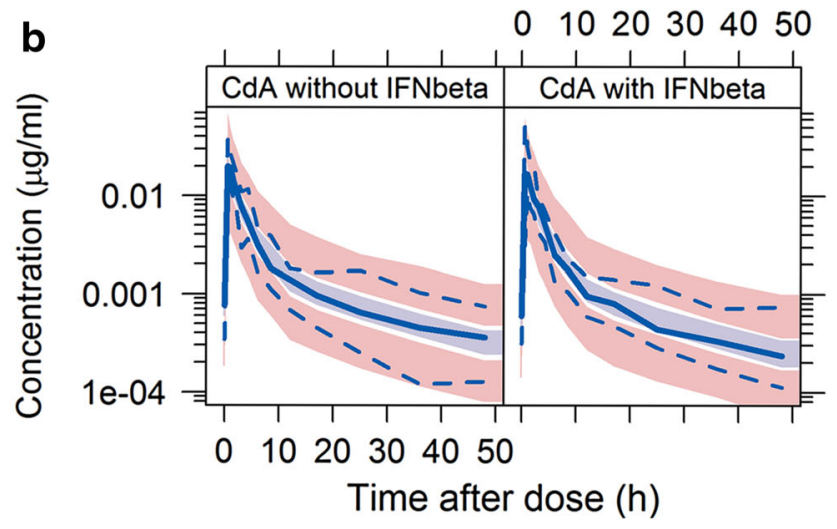

blue line indicates observed median; dashed blue line indicates observed 5th and 95th percentiles. (1) Based on 417 samples from 16 subjects; (2) based on 210 samples from 16 subjects; (3) based on 210 samples from 16 subjects; (4) based on 209 samples from 16 subjects. $C d A$ cladribine, $I F N$ interferon

author(s) and the source, provide a link to the Creative Commons license, and indicate if changes were made.

\section{References}

1. Leist TP, Weissert R. Cladribine: mode of action and implications for treatment of multiple sclerosis. Clin Neuropharmacol. 2011;34:28-35.

2. Leist TP, Vermersch P. The potential role for cladribine in the treatment of multiple sclerosis: clinical experience and development of an oral tablet formulation. Curr Med Res Opin. 2007;23:2667-76.

3. Giovannoni G, Comi G, Cook S, Rammohan K, Rieckmann P, Soelberg Sorensen P, et al. A placebo-controlled trial of oral cladribine for relapsing multiple sclerosis. N Engl J Med. 2010;362:416-26.

4. Lindemalm S, Savic RM, Karlsson MO, Juliusson G, Liliemark J, Albertioni F. Application of population pharmacokinetics to cladribine. BMC Pharmacol. 2005;5:4.

5. Svensson E, Acharya C, Clausson B, Dooley K, Karlsson MO. Pharmacokinetic interactions for drugs with a long half-life-evidence for the need of model-based analysis. AAPS J. 2016;18:171-9.

6. Keizer RJ, Karlsson MO, Hooker A. Modeling and simulation workbench for NONMEM: tutorial on Pirana, PsN, and Xpose. CPT Pharmacometrics Syst Pharmacol. 2013;2:e50.

7. Jonsson EN, Karlsson MO. Automated covariate model building within NONMEM. Pharm Res. 1998;15:1463-8.

8. Beal SL, Sheiner LB, Boeckmann A, Bauer RJ. NONMEM user's guides (1989-2009). Ellicott City: Icon Development Solutions; 2009.

9. Liliemark J. The clinical pharmacokinetics of cladribine. Clin Pharmacokinet. 1997;32:120-31.

10. Lindemalm S, Liliemark J, Juliusson G, Larsson R, Albertioni F. Cytotoxicity and pharmacokinetics of cladribine metabolite, 2-chloroadenine in patients with leukemia. Cancer Lett. 2004;210:171-7.

11. Saven A, Cheung WK, Smith I, Moyer M, Johannsen T, Rose E, et al. Pharmacokinetic study of oral and bolus intravenous 2-chlorodeoxyadenosine in patients with malignancy. J Clin Oncol. 1996;14:978-83. 